\title{
The "Present Referent": Nonhuman Animal Sacrifice and the Constitution of Dominant Albertan identity
}

\author{
Kelly Struthers MonTFORd
}

When a food or cuisine serves as a defining feature of a region, it is not a politically neutral process. Like most cultural phenomena, dominant foods emerge from struggles over meaning amongst contingent historical, social and political alliances. (Blue, "If it ain't Alberta" 73)

\section{Introduction}

On May 31, 2012, the "Hee Haw Collective" (composed of two Edmonton, Albertabased designers) called for posters conceptualizing "MEAT" (Hee Haw Collective, "Projects"). On August 30, 2012, the twenty posters selected by the Collective were hung in Edmonton. A coffee shop in the University area displayed the posters, as did a butcher shop (Hee Haw Collective, "Projects"). The poster collection will also be exhibited during the upcoming Works Art and Design Festival 2013 (Schutz). Inasmuch as the discourses communicated in these posters are largely pro-"meat"1 consumption, they reflect mainstream relationships to animals considered "food" in Alberta, dominant Albertan identity, and are consistent with the province's economic interests. In this paper, I analyze three posters from this collection and argue that the depiction of farmed animals in a state of living while illustrating connections to the "food" products they will become, stands in opposition to Carol Adams' (1990) popular theory of the “absent referent." Employing Derrida's (2003) concept of "sacrifice", I contend that in the Albertan context, the symbolic and literal sacrifice of nonhuman animals, particularly cattle, 
figures so prominently in the economic livelihoods and dominant heteromasculine identity of Albertans that the referent need not be absent ${ }^{3}$.

Alberta's main commodities are oil, gas, and cattle, wherein cattle (and other nonhuman animals) are instrumentalized for profit, and also where cattle-ranching plays a significant role in the construction of dominant identity, masculinity, and "virility" (Blue, "If it ain't Alberta"; Miller; Ward). With approximately 5.5 million cattle (as of 2010), Alberta is home to almost $40 \%$ of the cattle in Canada and has the largest cattle industry (including the sub-industries of breeding, raising/feeding, and "processing") among Canadian provinces (ABP, "Beef Production Chain"). According to the Alberta Beef Producers (ABP), cattle represent the province's largest agricultural market, at approximately one-third of total farming income ( $\$ 2.9$ billion). This industry is financially lucrative for the province as it results in "an overall benefit of over $\$ 11.6$ billion to the economy which would include primary production, processing, exports and retail sales" (ABP, "Industry Information"). The ABP are optimistic about their ability to maintain and increase their market-share both domestically and globally. For example, from 2000 to 2003, their "processing" market-share in Canada (slaughtering, packaging, etc.) grew to $72 \%$ ("Beef Production Chain"). The ABP are also seeking to find new consumer markets, such as China, as export destination in the near future. Overall this "translates into significant economic benefits for not only rural areas but the entire Alberta community" ("Industry Information”).

Cultural discourses relating to the oil, gas, and cattle industries function to underpin and maintain mainstream Albertan culture and identity. Specifically, romantic colonial tropes about the "frontier myth" and the "cowboy hero" inform understandings regarding extraction of natural resources, economic policies, and masculinity. The circulation of and attachment to the symbol of "the frontier" results in traditionally masculine traits being valued in this province: "Success 
in the harsh frontier environment required toughness and tenacity. And those qualities, which were originally required of ranchers and hired hands, are still admired. They have left cultural imprints on the contemporary scene" [emphasis in original] (Miller 61).

The symbolic power of the "cowboy hero," results in a socio-economic milieu imbued with "self-interest, competiveness, power and toughness [which] are characteristics of the frontier's enduring hero, the cowboy" (Miller 62). Wright argues that this logic underpins free market economics in the province, markedly, "the need for an open frontier, violence as a civil necessity, white male superiority, and an endlessly productive environment" (2). Within this economic logic, violence toward nature, nonhuman animals, and nonwhite humans inherent in the oil and cattle industries is obfuscated by a focus on their outcomes, namely, by an emphasis on industry and profit. It thus follows that violence against nature and certain groups becomes positioned as a necessary sacrifice for the constitution of dominant Albertan identity—an identity permeated by symbolic notions of a frontier and ranching way of life. Because of the positioning of violence as a means to what are perceived as more important (economic) ends, Carol Adams' (1990) widely accepted theory of the "absent referent"-which understands "meat"-eating as only possible through the psychological and physical separation of living animal from its "meat" products - is limited in explaining the practice of "meat"-eating in Alberta.

Instead, using the positioning of nonhuman animals in the posters herein analysed, I argue that Derrida's notion of sacrifice provides a theoretical lens through which to understand the ways in which the noncriminal putting to death of animals function as a necessary aspect in the maintenance of dominant Albertan identity and economic-wellbeing. This is because the well-being of ranchers and the local economy largely overshadow moral considerations for nonhuman animals, but especially for cattle, whose noncriminalized deaths function 
symbolically and literally as "sacrifices" (Derrida, The Animal That Therefore I Am, "Eating Well”; Wolfe, Animal Rites).

\section{Sacrifice and the Constitution of the "Human"}

In The Animal that Therefore I Am, Derrida traces the history of the concept of "the animal" in philosophical thought. In this ten-hour lecture, Derrida contends that "the animal" is symbolically (and literally) sacrificed in the construction of our culture. The death and suffering of farmed animals and those animals who are experimented upon can be understood as sacrifices inasmuch as their deaths are not legally prohibited (and are thus not cases of murder). Instead, these deaths are justified within humanist frameworks as required for the well being of humans. He argues that the subjection of the animal is integral to the construction of human subjectivity and the pursuit of human ends.

In Derrida's interview entitled "Eating Well," he explains that Western societies are governed by the logic of carnophallogocentrism, a symbolic and literal economy of animal sacrifice. Derrida problematizes the concept of "the animal," observing that it has been used by philosophers (such as Heidegger, Lacan, and Levinas) to present all nonhuman animals as so similar that they can be grouped together-their multiplicity denied. Derrida states that it is by opposing humans to the uniform concept of the animal that "the question of world" is specified (The Animal 149). He is referring to a world framed by humanism, in which questions surrounding what is proper to humans are solved through the "disavowal" of traits and abilities thought to be animalistic.

The animal is denied, among other traits, the capacity for intelligence, thinking, and reasoning. While Derrida (The Animal) and Cary Wolfe (who in Animal Rites and Before the 
Law extends Derrida's work on "the animal" to examine cultural manifestations of the discourse of animality) write that there is a plethora of evidence demonstrating that this is a false distinction, their purpose is not to challenge it. Rather, they seek to question how this notion of subjectivity has been established, and for Wolfe (Animal Rites, Before the Law), how it functions in society. They argue that this formation constitutes the basis of Western societies, specifically in that human subjectivity, law, and culture rely upon "carnivorous sacrifice" (Derrida, "Eating Well" 279).

Wolfe contends that the modern manifestation of the logic of "sacrifice" does not entail rituals that honour the life of the animal in question, but in material form their deaths are "regularized, routinized, and banalized in the services of a strategic, not symbolic, project" (Before the Law 27). The logic of sacrifice here underpins a system in which the subjection and instrumentalization of animals (and animalized human others) are justified as ends in the aims of maintaining the well-being of dominant humans.

Wolfe, employing the insights of Derrida to examine cultural manifestations (e.g., in film and in literature) of "the discourse of species," argues that it is these discourses that "in turn, reproduce the institution of speciesism" [emphasis in original] (Animal Rites 2). Wolfe defines this as:

An institution that relies on the tacit agreement that the full transcendence of the "human" requires the sacrifice of the "animal" and the animalistic, which in turn makes possible a symbolic economy in which we can engage in what Derrida will call a "noncriminal putting to death" of other humans as well by marking them as animal. (Animal Rites 6)

For Wolfe the beliefs that structure society are reflected through legal prohibitions and allowances. Thus notions of legality are fundamentally implicated in the "noncriminal putting to death" of some groups of humans and other animals; this relies upon, and is made possible by, 
"the discourse of animality" (Animal Rites 101). Even as this institution establishes a hierarchy of groups in that their distance from nonhuman animals and white men determines the worth of social, ethnic, and racialized human groups, it targets and exploits nonhuman animals to a vastly greater extent (Wolfe, Animal Rites).

Within this institution, "the latter [animal (non)subject] comes to be, in another sense, the nonsubject that is subjected to the human subject" (Derrida, The Animal 126). Specifically, nonhuman animals are sacrificed inasmuch as they are positioned and exploited within the logic of the institution of speciesism as "means for man: livestock, tool, meat, body, or experimental life form" (Derrida, The Animal 102). Yet it is also through their subjection to human ends that the institution is itself constituted and perpetuated, "human superiority is something which we construct through our instrumentalization of other species" [emphasis in original] (Taylor 75). Thus, the sacrificial structure of the cattle industry in Alberta helps constitute a system in which the instrumentalization of cows results in a lucrative provincial commodity.

The subjection of these animals as ends for humans works to construct dominant notions of Albertan identity, rural masculinity, and virility. Although it is possible that the "absent referent" could work within the logic of sacrifice in the process of denying subjectivity to nonhuman others, this is not the case in Alberta. As will be explained further below, this is for the reason that in Alberta-where dominant notions of identity are linked to violence, domination, and "survival" in the open frontier - the need to obfuscate violence is lost. Loyalty to the region is shown, and dominant identity reproduced through consumer support of the ranching lifestyle and the cattle industry's products, namely, "beef." 


\section{“Beef” and Alberta}

Blue writes, "some would go so far to argue that Alberta is beef" ("If it ain't Alberta" 70). The interconnections between the cattle industry and provincial identity function to maintain the prominence of "beef" consumption in the province (Blue "If it ain't Alberta"; Mauer) as well how the industry is able to manage, discipline, and silence dissent against this industry. The backlash against k.d. lang in 1990, and the silencing of former mayor of Calgary, Al Duerr, in 1995, provide two telling examples of the centrality of "beef"-culture in Alberta, and how this functions as a sacrificial economy in which regional identity and economy are maintained and reproduced.

When Alberta-raised musician k.d. lang made public her support of vegetarian diets and mentioned her knowledge of the cattle industry based on her growing up in a ranching community, her hometown, ranchers, and much of the province understood her as a traitor to the region. "This is where she comes from," one oilrig worker was quoted as saying, "this is a beefeating community. You don't screw where you come from" (qtd. in Korinek 333). The President of the National Farmers' Union stated that "if she's on some kind of a witch hunt or endangering the livelihood of cattlemen I would be in favour of not having anything to do with her music" (Easter qtd. in Korinek 332). For their part, some country music radio stations stopped airing her music since their advertising revenues were tied to cattle production (Korinek). Other backlash includes the Premier refusing to congratulate lang upon her Juno win three years later, polarized public discourse as reported by the media, and public attacks regarding her sexuality. For example, members of the Consort community defaced "home of k.d. lang" signs with "I Love Alberta Beef" stickers and one sign was spray-painted "eat beef dyke." These reactions 
demonstrate the symbolic power of "beef" in Alberta, and its importance to the economy and in the constitution of dominant Albertan identity.

Five years later, in October, 1995, then mayor of Calgary, Al Duerr, publically supported declaring October as "Vegetarian Month." Members of the Canada Beef Export Federation met Duerr's proclamation with backlash; the Chair of the Alberta Cattle Commission stated, "It is inconsistent for Calgary to support a vegetarian way of life" (Thorlakson qtd. in Maurer 65). Four days after his initial public support for a vegetarian month, Duerr retracted his public support. The following year, the Mayor's office declined to make a public statement regarding World Vegetarian Month, saying "When a subject is controversial, the conditions which make a proclamation acceptable no longer exist" (qtd. in Maurer 65). The economic place of cattle commodities in Alberta was strong enough to necessitate the Mayor's retraction of his support for a dietary lifestyle in opposition to this industry's interests. These cases of backlash show how the sacrificial economy of cattle is central to the maintenance and the prominence of this industry within the socio-political context of Alberta. The consumption of "beef" is positioned as a way to show affiliation to dominant Albertan identity, and to dominant provincial interests.

Blue's "If it ain't Alberta, it ain't Beef," traces and examines the 2003 BSE (Bovine Spongiform Encephalopathy) outbreak in Alberta's cattle. This event is a salient example of how the logic of sacrifice underpins "meat"/“beef" culture in Alberta. Blue shows that the BSE outbreak served to strengthen the Alberta "beef" economy as well as to strengthen ties between the constructed Albertan identity and the cattle industry. During the outbreak, the global trade of Canadian cattle was blocked, and the closure of US borders threatened to result in large financial losses for this industry. However, the ABP were able to financially profit from this outbreak 
(since borders were closed to live cattle, Alberta's slaughterhouses increased their share of the "processing" market).

Prior to this event people in Western countries had been reducing their consumption of "beef." Whereas the 1996 BSE outbreak in the UK resulted in British consumers further decreasing their beef consumption - a trend that had been occurring since the 1970s, largely for health reasons - the opposite occurred in Canada (Beardsworth and Keil; Blue, "If it ain't Alberta"). Canadians' "beef" consumption, which had been declining prior to the BSE outbreak, increased. Blue argues that this increase occurred due to the ABP's capitalization on this event, in which the province became largely unified in efforts to resist threats to its cattle industry ("If it ain't Alberta," "Branding beef"; Shukin). What this episode shows is that while the public was aware of the living origin of their meat (i.e., that the US border was closed to live cows), the financial implications of this ban and the marketing of $\mathrm{ABP}$ meant that the public continued to consume these cows as "beef" in order to support and show loyalty to the region's industry. As such, the deaths of these cows followed the logic of sacrifice as they were seen as a necessary measure to protect economic interests in Alberta (Carey; Derrida, The Animal, "Eating Well").

This mobilization of support was made possible by the province of Alberta's political environment of (perceived) consensus and Western Canadian alienation relative to other provinces, neoliberal economic policies, an economic and cultural history of dependency upon the cattle industry, and the dominant trope regarding the Albertan way of life:

The ABP's marketing strategy relies on a dominant tourist image associated with Alberta: a wholesome, wild, unsettled cattle country, relatively untouched by the advances of urban and technological culture, and miraculously retaining the spirit of the wild western frontier. One of its dominant discourses is that Albertan (and by extension Canadian) beef producers are in need of protection in order to save a way of life and a mode of production historically rooted in Alberta's history and culture. (Blue, "If it ain’t Alberta" 75) 
Here, the consumption of "beef" is positioned as a way to resist threats to the closing of US borders to trade, and the symbolically powerful and "threatened" Albertan way of life (i.e., traditional ranching and "wholesome" family values). Although the ABP appeals in their marketing to traditional/historical production techniques and small-scale family farming, in reality, the Alberta "beef" industry relies on the same industrialized practices, as do other largescale producers. It is for this reason that this industry is so profitable (ABP, "Beef Production Chain," "Marketing Campaigns"; Blue, "If it ain’t Alberta," "Branding Beef").

The ABP championed a powerful effort to manage the BSE outbreak in 2003. Industry advocates in Alberta joined together to rebrand this product; public funds were made available to those affected, "a cross-country barbeque dubbed the 'World's Largest Barbeque' was organized by culinary activist Anita Stewart" (Blue, "If it ain't Alberta" 71), and chefs showed their support to the cause by specially featuring Alberta "beef" in their restaurants. As MacDonald wrote of the BSE outbreak:

Americans may have stopped Canadian beef from flowing over the border but Albertans fought back with the "I Love Alberta Beef" bumper sticker. It seemed as though every driver in the province had slapped a bumper sticker to the tail end of their Chevy, Ford or Dodge. Their message was simple: Eat more beef. And love it. (qtd. in Blue, "If it Ain't Alberta" 71)

The ABP capitalized upon the BSE outbreak in such a way as to strengthen the relationship between Alberta and "beef." The crisis remained deeply linked to dominant Albertan values and economic considerations. The noncriminal putting to death of cattle during the time of the BSE episode demonstrates the employment of the logic of sacrifice in that their deaths were encouraged as a form of food activism in support of the industry, the region, and the population. 
The call for "MEAT" posters by the Hee Haw Collective reflects links between the sacrifice of cows in the production of identity, economy, and culture in the Albertan context.

\section{The Hee Haw Collective and a "MEAT" Themed Summer}

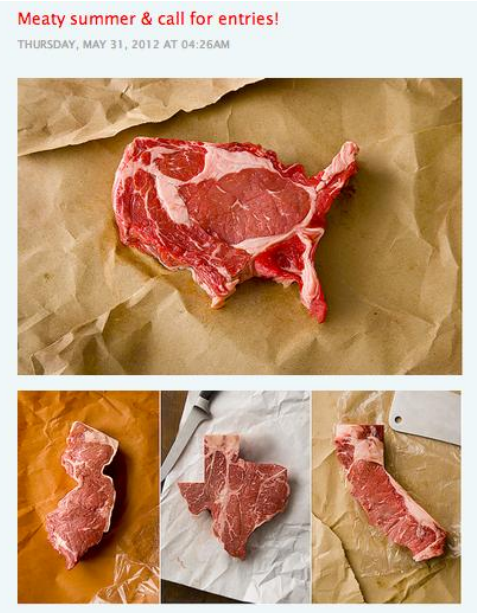

The Hee Haw Collective provides a means for Edmonton designers to share their work with average citizens. Each year, it invites local artists to submit poster designs according to the Collective's chosen theme. The Collective says it functions "for the pure joy of the creative process and sharing messages with others" [emphasis added] (Hee Haw Collective, "About"). The founders recognize that the posters they select are not neutral. The fact that these posters were hung throughout the community, and that the collection will be displayed at an art show, demonstrate that the discourses are circulating in an aesthetic register as well ${ }^{4}$. I contend that the "MEAT" posters function according to the logic of sacrifice in order to support and maintain powerful and dominant economic and political interests in Alberta.

For example, the photo shown above features animal flesh carved into the shapes of the United States, and of three cattle producing states (California, Texas, and New Jersey) (United 
States Department of Agriculture, "United States: Cattle”). The photos of cow flesh ("steaks") also demonstrate that the consumption of nonhuman animals was central to the Collective's conceptualization of "MEAT." This project also made use of the flesh of nonhuman animals in their poster launch party. For example, the invitation to the unveiling stated: "Follow the smell of smoked meat up the stairs to the WD studio." The Hee Haw Collective also planned for the posters to be hung on August 15, 2012_-"prime BBQ season” (Hee Haw Collective, "Projects”). As such, the Collective was direct in linking "meat" to animal flesh and consumption.

The fact that the Collective launched its messages during "prime BBQ season" demonstrates that they assumed their posters would not deter, but reinforce, the consumption of nonhuman animal flesh (Hee Haw Collective, "Projects"). Here, the slaughter of nonhuman animals functions as a sacrifice. The noncriminal putting to death of these animals serves a social function for humans in that their consumption as "meat" serves to create and/or define membership to a community (Foer; Pollan; Spencer). Many ranchers and farmers in Alberta are financially dependent upon the raising and death of farmed animals. Within a humanist framework, the violence inflicted upon nonhuman animals does not compare to the importance placed upon the well-being of ranchers and farmers, and the maintenance of dominant Albertan identity.

Indeed, the name "Hee Haw" connotes a rural, Western, cowboy lifestyle/orientation. The name is also reminiscent of the syndicated CBS television variety show, "The Hee Haw Collection." This show featured comedy skits and music performances by country artists. Although this show aired from 1969-1987 in syndicated formats, CBS cancelled the show in 1971 for the reason that "it was "too rural"" (IMDB). The Collective employs animal eating in ways that appeals to idealized rural values that underpin notions of identity in Alberta. 
Specifically, the Collective's "MEAT" campaign appears to use nonhuman animals (imagined as "meat") as a way to celebrate dominant Albertan identity.

These posters are social documents suitable for analysis inasmuch as they are considered in the circumstances they were produced (i.e., The Hee Haw Collective's project) (MacDonald). These are not neutral representational texts, but mandate, through a visual medium (Marvasti), specific ways of understanding humans' relationships to nonhuman animals consumed as food, and relationships between food and identity. Specifically, these posters largely celebrate and/or encourage the consumption of nonhuman animals while referring to the living origin of "meat."

\section{'Meater': Alberta and the "Present Referent"}

Given the focal role of the cattle industry in the regional economy, and in the reproduction of identity and belonging in this province. Carol Adams' (Sexual Politics of Meat) concept of the "absent referent" is of limited use in explaining the continued consumption of nonhuman animal flesh in the Alberta context. Her idea first appeared in The Sexual Politics of Meat, a book described by The Boston Globe as "a bible of the vegan community" (qtd. in Adams back matter). It frames an argument in which the human consumption of nonhuman animal flesh is made possible by the physical and psychological separation of flesh (what many humans consider food) from its origin as a living and feeling being. Specifically, it is defined as "...what separates the meat eater from the animal and the animal from the end product" (13). Adams writes that the absent referent functions in three manners: through death, through language, and through animalized experiences (Sexual Politics of Meat).

It is through their slaughter (and thus their absence as living animals) that they are made into food for humans; through language, in that food items from animals are renamed in ways 
that can obfuscate their origin (e.g., calf becomes "veal," cows become "beef," pig becomes “bacon”); and through humans' (particularly women's) use of animalized experiences to describe their experiences (e.g., "I was treated like a piece of meat"). This comparison of human and nonhuman animal experiences functions to create an artificial distinction between these groups; it also dismisses the suffering of nonhuman animals inasmuch as it becomes acceptable to treat nonhuman animals in ways unacceptable for humans (Adams, Sexual Politics of Meat). ${ }^{5}$

Much popular literature that argues for non-exploitative relationships between humans and other animals - literature in which veganism (in diet, cosmetics, and goods) is frequently espoused-does so by making the referent present (Adams, Pornography of Meat, Sexual Politics of Meat; Foer; Freedman and Barnounin; Joy; Robbins; Singer). Specifically, these authors provide information and education regarding the realities of agri-business. This body of work exposes the suffering of animals who are seen as mere commodities, the environmental degradation that results from these industrial practices, the health implications for humans and communities, and the exploitation of workers (especially nonwhite) in low-paying and extremely

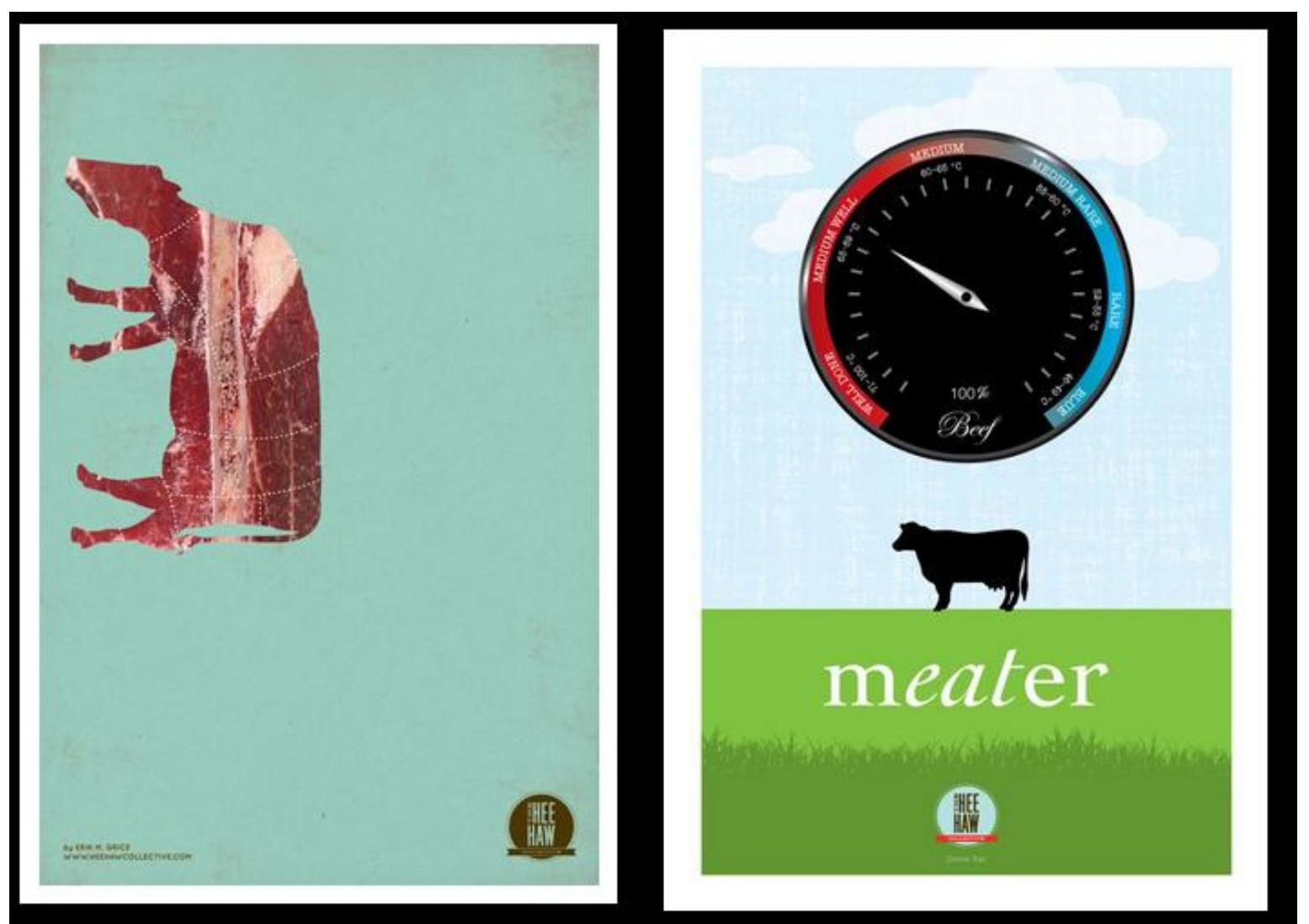


dangerous slaughterhouse work (Blue, "If It Ain’t Alberta"; Fitzgerald; Foer; Joy). In varying ways, the above-mentioned authors assume that in making the absent referent obvious, peoples' ethical orientation to the consumption of nonhuman animals will be questioned and changed. However, in Alberta, the referent need not be employed given the role of the "beef" industry in the regional economy, and its ties to dominant identity.

These posters ("untitled" and "meater") do not, for instance, shy away from the depiction of animal life. While the cows are presented as outlines containing raw "meat," or shaded in black, their living is referred back to via the activities they are depicted as engaging in (standing, presumably grazing) - they are not prepackaged as products without recognition to their origin. The question as to whether the audience would be made uncomfortable by these images, which refer to the origin of "meat" from cows, is unlikely given the above discussed call for posters, as well as the fact that a butcher shop hung them.

Adams states "if animals are alive they cannot be meat" (Sexual Politics of Meat 66); but in these posters the cows are not only present, but are also reconfigured as food commodities while still alive. In one ("untitled") poster, the cow is positioned as alive but skinned, and eating what is presumably grass. This is in opposition to Adams' claim; for her, one way that the absent referent is made possible is by a combination of "nonhuman animal + butchering" (Pornography of Meat 23). However, this cow is also depicted as the cuts/parts she will be sold as once slaughtered and butchered. While her "aliveness" is not denied, her living is positioned as merely a means to human ends - her consumption of food, the human consumption of her. Similarly, a poster entitled "meater" presents a living cow with a temperature gauge above her, including the corresponding temperatures and categories for cooking "steak." The term "meater" appears to have four functions and implications. First, it functions as a homonym of and a play on the word 
"meter," which refers to the temperature gauge. Second, the cow herself is depicted as living "meat." Third, the word serves as an identity marker for the carnist ${ }^{6}$ viewer, and fourth, as a directive to the audience: eat-er (eat-her). Both these posters however, present faceless, passive female objects (they lack horns, and the cow in "meater" has a visible udder). They are examples of what Derrida calls "the nonsubject"- they cannot be anything other than means to human ends (The Animal). Viewers are implored to consume these animals that are noncriminally put to death for the benefit of humans.

Again, this cow is not in a state of being divorced from her eventual fate as flesh to be consumed by humans, but is deemed to be "beef" while still living. While the explicit suffering entailed in slaughtering and butchering nonhuman animals for human ends is not shown in these posters, showing this cow as alive while suggesting she be cooked and eaten is inescapably violent. Inasmuch as these cows are depicted in these posters as eating grass on open plains, they are not necessarily "factory farmed" (although they are consistent with the logic of factory farming), and provide an example of the material operation of the logic of sacrifice:

The value conferred upon the animal in an act of sacrifice is immediately appropriated and instrumentalized in the service of propping up a vision of humanity that not only reinforces humans as the ultimate masterful predators and subjects, but also resonates and works in total harmony with the similarly humanity-serving value conferred upon the factory farmed animal by the late capitalist system - that is, the animal figured as both commodified and financialized value." (162)

What Carey is describing above, and what is gestured towards in the titles of these posters "untitled" and "meater" show that these animals are denied subjectivity, and instead are reconfigured as living food production units. While Adams agrees that the absent referent functions to deny subjectivity to animals, she is adamant that connections between "meat" and its origin are integral to the functioning of this disassociation: "once the existence of meat is 
disconnected from the existence of an animal who was killed to become that 'meat,' meat becomes unanchored by its original referent (the animal), becoming instead a free-floating image" (13). Inasmuch as these posters depict the animal and the "meat" products she will become, they are inconsistent with the logic of the absent referent.

Although it might be argued that the absent referent is a necessary step in the process of dehumanization that Derrida discusses in his notion of sacrifice, it is not a required step in the noncriminal putting to death of animals, as the local food movement (which will be further explained below), home butchery, and the trend for foodies to eat "snout to tail" (Cole; Rudy; Weiss) makes evident. Adams assumes that if humans knew where and from what conditions their "meat" originated, they would be morally unable to consume it. Thus Adams presumes humans inherently have a moral obligation to animals. Specifically, that it is only through disassociation and obfuscation that humans are able to consume "meat" (i.e., they remain ignorant to its origin).

Sacrifice, instead presumes that justification for the instrumentalization of animals relies upon a humanist framework wherein the consumption of animals serve human ends (Carey; Derrida, The Animal). As Carey writes:

The apparatus of sacrifice articulates a logic wherin humanity immunizes itself from excessive implication, entanglement, and identification with animal life by deeming animals killable. Yet in order for this symbolic designation to be seen as legitimate according to the definition of sacrifice, the sacrificial 'killability' of animals needs to serve an end. (63-4)

In Alberta, the noncriminal putting to death of animals functions according to the logic of sacrifice in which their deaths operate as ends, in this case, for human "nourishment", for the regional economy, for the livelihoods of many Albertans, and for the maintenance of Albertan identity and heritage. Thus the absent referent need not be employed in this context inasmuch as 
nonhuman animals are positioned as necessary sacrifices in the preservation of the Albertan way of life (Blue, "If it ain't Alberta"; Derrida, The Animal; Wolfe, Animal Rites, Before the Law).

\section{Local Foods, Loyalty and Historical Preservation Through “Beef” Consumption}

The discourses communicated in the "Why Buy Local?"7 poster demonstrate that the "local food" movement has reconfigured ethical questions regarding "meat"-eating, this has occurred in ways that are consistent with the logic of sacrifice, specifically in that nonhuman animals are positioned as a means for human ends. This poster positions the consumption of local "meats" (but especially "beef") as a way to preserve "historical"8 Albertan roots. This appeal to "origin" writes Alberta as a white province by ignoring Aboriginal origin and histories of colonization. An analysis of the discourses communicated in this poster also provides an opportunity to examine cultural practices of meat-eating and their relation to dominant notions of masculinity, virility, and identity.

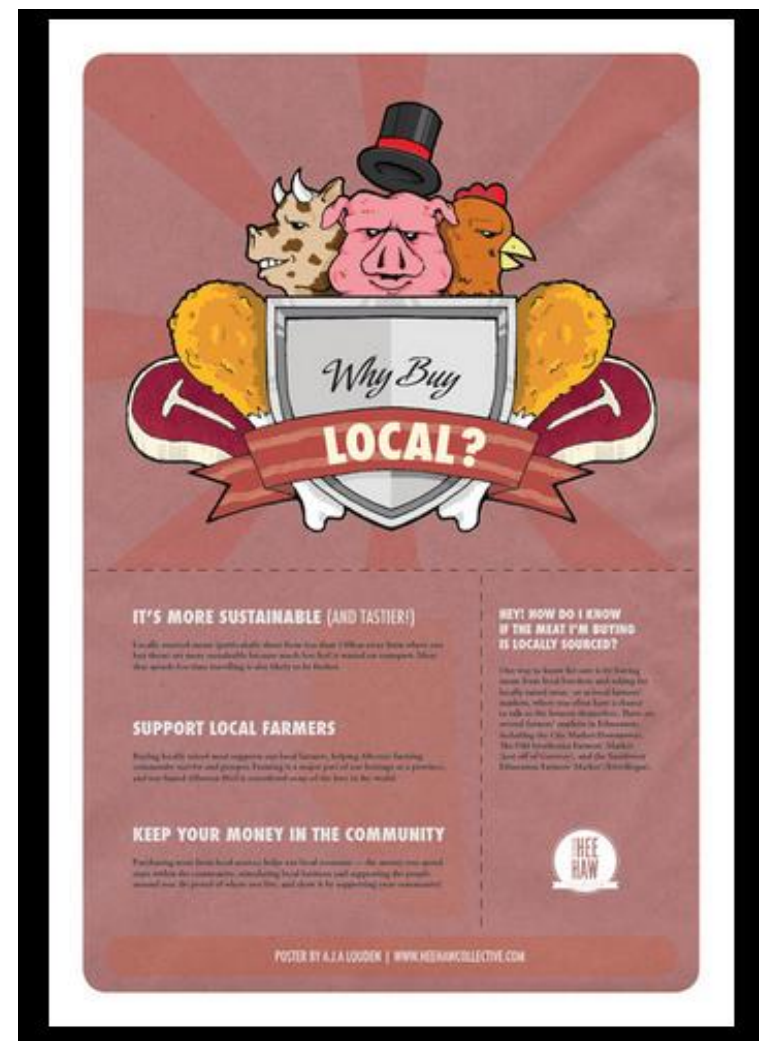


The discourses in this poster tell Albertan consumers that shopping locally is a way to respect their historical roots, to shop ethically, and to support their communities. Farmed animals are shown as whole and alive; the food parts they are butchered for are pictured beside them. Although this poster features a cow, a pig, and a chicken, the text employs the symbolic power of "Alberta Beef," and states: "Our farmed Alberta beef is considered some of the best in the world." The promotion of Alberta "beef" is accomplished by appealing to the dominant trope of Alberta's ranching history: "Buying locally raised meat supports our local farmers, helping Alberta's farming community survive and prosper. Farming is a major part of our heritage as a province." Here, the non-criminal putting to death of animals functions as a sacrifice as their consumption is positioned as a means to help protect a way of life that is promoted by the ABP as both threatened and uniquely preserved in Alberta (Blue "If it ain't Alberta"; Korinek).

The text encourages the audience to show their support to their community through consumer spending: "be proud of where you live, and show it by supporting your community!" Yet it is the killing and sale of the animals featured in this poster that provide the grounds in which "community" can be built. It is their exclusion from the human community that allows their deaths to be categorized as both non-criminal and as necessary for human (and community) well-being.

Discourses surrounding locavorism tell consumers that specific relationships to community, economy, and environment are realizable through this practice, which entails an:

Ecologically-aware relationship with our food, and [it] promotes eating practices that enhance rather than degrade environmental and human health, while also providing meaningful consumer participation in practices of ecological stewardship. (Mallory 172) 
This poster, however, co-opts this concern and instead appeals to the believed ethical superiority of locavorism as a way to encourage the economic support of regional "meat" producers. The consumption of farmed animals is promoted in this poster as beneficial to the local economy, to human taste buds, and to the environment.

The discourses operating in the "Why Buy Local Poster?" are in fact counter to the principles underpinning locavorism. Absent from this poster is the inefficiency (not to mention vast amounts of cruelty) inherent in the production of "meat," the detrimental effects to the environment, and how grains fed to farmed animals could be redistributed to marginalized humans in both developed and developing nations (instead of being used to raise animals which only those in the first world will consume) (See Beardsworth and Keil; Foer; Joy; Milligan; Robbins; Singer; Stanescu). The imperative to consume local animals in this poster is largely economic, and reflects the centrality of "beef" and rancher identity in Alberta.

The local foods movement and the discourses surrounding it also complicate the theory of the absent referent. Adams' especially employs the anxieties surrounding factory farming to justify the necessity of the "absent referent" in explaining "meat" eating (Sexual Politics of Meat). However, with the increased popularity of "happy [local, small scale] meat" ethical questions regarding the consumption of animal flesh are reconfigured, and the limits of the absent referent theory are further revealed:

As the local farm is enthusiastically taken up by "foodies," the raising and slaughtering of food animals is more a part of culture today than anytime in the last sixty years. From major media moguls like Martha Stewart and Oprah Winfrey, to popular and accessible chefs like Rachel Ray to Mark Bittman, the message is univocal: know firsthand the conditions your food animals are raised in and if you can, butcher (and if possible slaughter) them yourselves. Indeed, Stewart, Ray, and a host of chefs on Food Network regularly visit farms to meet their animals before they become food. (Rudy 28) 
This ethical orientation gives consideration to the quality of life animals experience prior to and (sometimes) during their slaughter, but not to whether nonhuman animals should be used in the service of humans as food (Cole). Weiss' research regarding the locavore movement and "foodies" in pig producing North Carolina further challenges the absent referent. In particular, the parts of the pig's body in which it is least possible deny the living origin of their "meat" (e.g., the head), are now highly coveted. For example, he writes of an "underground" butchery course he attended:

On the first night, the crowd was able to help dress a live pig for barbecue (i.e., to slaughter and clean the animal carcass so that it could be slow-roasted whole.) In addition to emphasizing the seamless connection between the living animal and its ultimate consumption, this event was notable for the way that the pig's parts were made use of. To begin with, the head had already been spoken for-meant to be rendered into headcheese, of course. (621)

Instead of "meat"-eaters experiencing trepidation regarding their consumption of animals when confronted with their aliveness, as the absent referent assumes, locavores in this instance sought connections with the animals (mainly via relationships with farmers) they ate:

'I'm eating meat from an animal that had been treated well and then turned into food'.... This sentiment is routinely offered by customers at the farmers' market stands where I work each week. Clearly, the presence of the animal — and in some regards, a continuity of the animal's life into the act of consumption, rather than an ellipsis between them-is valued by such consumers. (Weiss, 620)

In this case, consumers understand the function of animals as necessary sacrifices in the disruption of industrial agricultural systems, a means to preserve "heritage" breeds of pigs, and as a way to support their local economy (Weiss). Similar to Alberta, North Carolina is a state economically dependent upon the death of certain farmed animals. In both instances, consumers are not unaware of the origin of their "meat." Instead, the logic of sacrifice operates to position 
the consumption of nonhuman animals as an ethical consumer choice necessary to the maintenance of local communities, aspects of heritage and economy.

Masculinity, virility, and "meat" consumption. Unlike the posters above that feature female cows, the animals (bull, pig, rooster) in this poster appear to be male and aggressive. They are also made to look "ugly" and not "cute." This works to reinforce their consumption as food by humans who are more reluctant to eat "cute" animals such as sheep, deer, and rabbit, as opposed to pig, cow, and chicken who are considered "dirty," "dumb," and/or "mean" (Dunayer; Heldke; Joy). These animals also have facial features, which mark them as individuals. The artist also depicts them as hostile - they have furrowed brows, and the bull is bearing his teeth. The question as to whether the artist intended to personify, specifically the pig (by marking him with a top hat), remains unclear. The portrayal of aggression (which is reasonable in the context of being eaten by humans as food) can also function to inflate/reinforce human dominance over nature by conquering and consuming aggressive animal others (Adams, Pornography of Meat, Sexual Politics of Meat; Miller; Taylor, Ward).

The discourses communicated in this poster are consistent with the ethos of "beef" in Alberta, and the relationship between masculine domination of nature and animals in the context of the frontier of Alberta. Furthermore, in the context of Alberta, it is because of their death (sacrifice), in part, that dominant Albertan identity and community is constituted and maintained (Derrida, The Animal, "Eating Well"; Wolfe, Animal Rites). The instrumentalization of nonhuman animals and the consumption of their bodies continue to function as a means for "man" to place himself outside of nature and the animalistic (Derrida, The Animal, "Eating Well"; Taylor; Wolfe, Before the Law). 
Wolfe asks whether it is sacrifice, or, the taking of life that entails the phallocentric assertion of humans over other animals that "makes meat, "meat" (Before the Law 97). The cultural norms attached to "red meat" relate to intersecting notions of race, gender, class, and sexuality, wherein its consumption is a practice of masculinity. The symbolic meaning attached to "red meat" is related to higher concentrations of blood, which "is associated with virility, strength, aggression and sexuality" (Beardsworth and Keil 210; Twigg). This framework fails to consider that the blood so held in high esteem is that of (mostly) female herbivores. Regardless, "meat" eating functions as an expression of traditional (white) masculinity (Adams, Sexual Politics of Meat; Bailey; Beardsworth and Keil; Breeze Harper; Buerkle; Potts and Parry; Taylor).

\section{Conclusion}

In this paper, I have argued that the concept of sacrifice is more appropriate to describe "meat"-eating in Alberta than the concept of the absent referent (Adams, Sexual Politics of Meat). I have done so by analyzing three posters that demonstrated that the prominence of the cattle industry relative to Alberta's economy, and its ties to the production and reproduction of dominant Albertan identity, largely do not pose ethical concerns regarding whether nonhuman animals should be eaten in the first place. In fact, these posters celebrated the consumption of "meat" and unabashedly made evident the living animal origins of "meat." The noncriminal putting to death of nonhuman animals can instead be understood as symbolic and literal sacrifices in the constitution of dominant Albertan identity and economy. The posters published by the Hee Haw Collective are mainstream cultural products and are consistent with pro-"meat" discourses that circulate in Alberta. 
Specifically, an analysis of the three posters herein discussed revealed that the ethical concerns that underpin Adams' concept of the absent referent - that humans would cease eating "meat" if they knew of its origin — are of limited applicability in Alberta. Instead, these posters showed that "meat"-eating involves socio-economic and political contexts and questions "about how culture, identity, and meaning are produced in part through practices of procuring and consuming particular foods" (Joy; Mallory 11; Milligan; Taylor). As such, this paper makes an intervention into ecofeminist literature as well as vegan literature written for mainstream populations that rely on the absent referent to explain and thus counter "meat"-eating practices (Adams, Pornography of Meat, Sexual Politics of Meat; Foer; Freedman and Barnounin; Joy; Robbins; Singer). The symbolic and literal sacrifice of nonhuman animals, particularly cattle, figures so prominently in the economic livelihoods and dominant heteromasculine identity of Albertans that the referent need not be absent.

In the context of Alberta, the tropes of the frontier and the cowboy hero function to ingrain human (and particularly masculine) domination over nature (Miller; Ward); the raising, killing, and consumption of nonhuman animals is but one manifestation of this. The discourse of solidarity to the region combined with an imagined social homogeneity effectively functions to position the consumption of "beef" as an expression of loyalty to the region, and as a means to preserve Alberta's (imagined) heritage (Blue, "If it ain’t Alberta"; Korinek). The strength of the cattle industry results in ABP's swift management and disciplining of political resistance to "meat"-eating in Alberta (Blue, "If it ain’t Alberta"; Korinek; Mauer).

Within a humanist paradigm, the wellbeing of ranchers and farmers trump ethical considerations of nonhuman animals used as means for human ends (Derrida, The Animal; Wolfe, Animal Rites, Before the Law). Thus, the cattle industry and dominant Albertan identity 
are underpinned by the institution of speciesism in which nonhuman animals are positioned as sacrifices and are non-criminally killed as means to human ends (Derrida, The Animal, "Eating Well"; Wolfe, Animal Rites). In conceptualizing "meat"-eating in this way, we can begin to understand "food" choices in relation to political, economic, and socio-cultural factors and constraints (instead of asking after what information is hidden from the general public) Future research should consider whether Alberta is an isolated case, or if economic dependence upon farmed animals in other geographical locations also demonstrates the limitations of, and complicates the theory of the absent referent.

\section{Notes}

${ }^{1}$ Note that throughout this article I use scare quotes to signal my disagreement with terms that unquestionably position nonhuman animals as food for humans, with terms that rename animal flesh as food commodities for human consumption (e.g., "meat," "steak," "beef," etc.), and with terms that obscure the violence inherent in the raising, slaughtering, and butchering of nonhuman animals (e.g., in industry terms, the killing and butchering of nonhuman animals is referred to as "processing"). I however, have not altered how other authors use the term "meat" when quoting them.

${ }^{2}$ Note that I do not engage in a Derridean deconstructive reading of the texts herein analyzed, but rather draw upon his substantive arguments regarding nonhuman animals and contemporary culture.

${ }^{3}$ This paper analyses the Alberta context only. It would be worthwhile in the future to consider whether Adams' (Sexual Politics of Meat) concept is unable to explain the consumption of "meat" in general, or whether other locations that are economically dependent upon animal/fishing industries are speciesist in similar ways.

${ }^{4}$ Although these images are circulating within an aesthetic register, and that animal outlines are currently trendy cultural products in Western societies, I focus on the messages communicated within these images, especially since the Hee Haw Collective is explicit in their position that they communicate messages ("About us"). While these outlines are common mainstream images at the present time, the links made between living animals and their future as food, as well as the encouragement of their consumption, makes these posters worthy of consideration. 
5 Although my argument is premised on the limited power of the "absent referent" to explain flesh eating in Alberta, Pallotta's research regarding children's exposure to nonhuman animal suffering suggests that the referent is very powerful and traumatizing for children. This is because they have not yet been socialized to consider animals as means for human ends. He does however suggest the possibility that his participants were inclined from a very young age to exhibit empathy towards other animals.

6 Joy argues for the use of the term "carnism" to describe "meat"-eating. Since humans do not require nonhuman animal flesh for their survival, like do carnivore animals, she concludes that "meat"-eating is a reflection of a belief regarding human-nonhuman relationships. As such, "carn" means flesh, and "ism" refers to a belief system.

7 The "Buy Local" text reads:

(1). Locally sourced meats (particularly those from less than $190 \mathrm{~km}$ away from where you buy them) are more sustainable because much less fuel is wasted on transport. Meat than spends less time travelling is also likely to be fresher.

(2). Buying locally raised meat supports our local farmers, helping Alberta's farming community survive and prosper. Farming is a major part of our heritage as a province, and our farmed Alberta Beef is considered some of the best in the world.

(3). Purchasing meat from local sources helps our local economy-the money you spend stays within the community, stimulating local business and supporting the people around you. Be proud of where you live, and show it by supporting your community!

(4). One way to know for sure is by buying meats from local butchers and asking for locally raised meat, or at local farmers' markets, where you often have a chance to talk to the farmers themselves. There are several farmers' markets in Edmonton, including the City Market (Downtown), The Old Strathcona Farmers' Market (just off Gateway), and the Southwest Edmonton Farmers' Market (Terwilleger).

8 The ABP promotes Alberta "beef" as a product of nonindustrialized, and thus historical ranching techniques. However, as Blue ("If it ain't Alberta") explains, this is false, and is simply a marketing technique employed by the ABP.

${ }^{9}$ The works that Derrida examines in The Animal commonly position men as universal subjects in the constitution of "human." There also continues to be a historical and enduring gendered aspect regarding the consumption of nonhuman animals - specifically, that "meat"-eating is a masculine endeavour (Adams, Pornography of Meat, Sexual Politics of Meat; Bailey; Beardsworth and Keil; Breeze Harper; Buerkle; Preece; Spencer; Taylor). 


\section{Works Cited}

Adams, Carol. J. The Pornography of Meat. New York: Continuum, 2003.

-. The Sexual Politics of Meat: A Feminist-Vegetarian Critical Theory. $20^{\text {th }}$ Anniversary

Edition ed. New York: Continuum International Press, 2010.

Alberta Beef Producers. Beef production chain. 2013.Web. 1 Apr. 2013.

—.Industry Information. 2013.Web. 1 Apr. 2013.

—.Marketing Campaigns. 2013.Web. 1 Apr. 2013.

Bailey, Cathryn. "We are what we Eat: Feminist Vegetarianism and the Reproduction of Racial Identity." Hypatia 22, no. 2 (2007): 39-59.

Beardsworth, Alan, and Teresa Keil. "The Mysterious Meanings of Meat." Sociology on the Мепи. New York: Routledge, 1997. 193-217.

Blue, Gwendolyn. "If it Ain't Alberta, it Ain't Beef: Local Food, Regional Identity, (Inter)national Politics." Food, culture, and society 11, no. 1 (2008): 69-85.

—. "Branding Beef: Marketing, Food Safety, and the Governance of Risk." Canadian Journal of Communication 34 (2009): 229-44.

Breeze Harper, A. "Going Beyond the Normative, White, 'Post-Racial' Vegan Epistemology." Taking Food Public: Redefining Foodways in a Changing World. Eds. Psyche Williams Forson and Carole Counihan. New York: Routledge, 2011. 155-74.

Buerkle, Wesley. "Metrosexuality can Stuff it: Beef Consumption as Heteromasculine Fortification." Taking Food Public: Redefining Foodways in a Changing World. Eds. Psyche Williams Forson and Carole Counihan. New York: Routledge, 2011. 251-64.

Carey, Jessica. Humane Disposability: Rethinking 'Food Animals,' Animal Welfare, and Vegetarianism in Response to the Factory Farm. Dissertation, McMaster University. Open Access Dissertation and Theses, 2011. (Paper No. 6104).

Cole, Matthew. "From 'Animal Machines' to 'Happy Meat'? Foucault's Ideas of Disciplinary and Pastoral Power Applied to 'Animal-Centred' Welfare Discourse.” Animals 1 (2011): 83-101.

Derrida, Jacques. “'Eating Well,' or the Calculation of the Subject.” Points...Interviews, 1974-1994. Ed. Elisabeth Weber. Standford: Stanford University Press, 1995. 255-88. 
- The animal that therefore I am [L'animal que donc je suis]. Ed. Marie-Louise Mallet. Trans. David Wills. New York: Fordham University Press.

Dunayer, Joan. "Sexist Words, Speciesist Roots." Animals and Women: Feminist Theoretical Explorations. Eds. Carol. J. Adams and Josephine. Donovan. 1st ed. Durham: Duke University Press, 1995. 11-31.

Fiddes, Nick. Meat: A Natural Symbol. New York: Routledge, 1991.

Fitzgerald, Amy. "Doing Time in Slaugtherhouses: A Green Criminological Commentary on Slaughterhouse Work Programmes for Prison Inmates." Journal for Critical Animal Studies 10, no. 2 (2012): 12-46.

Foer, Jonathon Safran. Eating Animals. 1st ed. New York: Little, Brown and Company, 2009.

Freedman, Rory, and Kim. Barnounin. Skinny Bitch. Philadelphia: Running Press Book Publishers, 2005.

Hee Haw Collective. About. N.d. Web. 1 Apr. 2013.

—. Meater. 2012. Web. 1 Apr. 2013.

—. Projects. 2012. Web. 1 Apr. 2013.

—. Untitled. 2012. Web. 1 Apr. 2013.

—. Why Buy Local? 2012. Web. 1 Apr. 2013.

Heldke, Lisa M., “And Reader, We Ate It.” Exotic Appetites: Ruminations of a Food Adventurer. New York: Routledge, 2003: 69-88.

IMDB. Hee Haw. 2013. Web. 1 May 2013.

Joy, Melanie. Why we Love Dogs, Eat Pigs, and Wear Cows. San Francisco: Conari Press, 2010.

Korinek, Valerie J. "'Meat stinks/Eat Beef Dyke!' Coming Out as a Vegetarian in the Prairies." Edible Histories, Cultural Politics: Towards a Canadian Food History. Eds. Franca Iacovetta, Valerie. J. Korinek, and Marlene Epp. Toronto: University of Toronto Press, 2012. 305-48.

MacDonald, Keith. "Using Documents." Researching Social Life. Ed. Nigel Gilbert. 3rd ed. Los Angeles: Sage, 2008. 285-303. 
Mallory, Chaone. "Locating Ecofeminism in Encounters with Food and Place." Journal of Agriculture and Environmental Ethics (2012).

Marvarsti, Amir. "Writing and Presenting Social Research." The SAGE Handbook of Social Research Methods. Eds. Pertti Alasuutari, Leonard Bickman, and Julia Brannen. Thousand Oaks: SAGE, 2008. 602-16.

Mauer, Donna. "Charting the Contemporary Vegetarian Movement in the Social Movement Field." Vegetarianism: Movement Or Moment? Philadelphia: Temple University Press, 2002. 4769.

Miller, Gloria E. "Frontier Masculinity in the Oil Industry: The Experience of Women Engineers." Gender, Work, and Organization 11, no. 1 (2004): 48-73.

Milligan, Tony. Beyond Animal Rights: Foods, Pets and Ethics. New York: Continuum, 2010 .

Pallotta, Nicole. R. "Origin of Adult Animal Rights Lifestyle in Childhood Responsiveness to Animal Suffering." Society and Animals 16 (2008): 149-70.

Potts, Annie, and Jovian. Parry. "Vegan Sexuality: Challenging Heteronormative Masculinity through Meat-Free Sex." Feminism \& Psychology 20, no. 1 (2010): 53-72.

Preece, Rod. Sins of the Flesh: A History of Ethical Vegetarian Thought. Vancouver: UBC Press, 2008.

Robbins, John. No Happy Cows: Dispatches from the Frontlines of the Food Revolution. San Francisco: Red Whell/Weier, 2012.

Rudy, Kathy. "Locavores, Feminism, and the Question of Meat." The Journal of American Culture 35, no. 1 (2012): 26-36.

Schutz, Amanda. "Hee Haw Collective Copyright Permissions." Message to the author. 15 Apr. 2013. E-mail.

Shukin, Nicole. Animal Capital: Rendering Life in Biopolitical Times. Minneapolis: University of Minneapolis Press, 2009.

Singer, Peter. Animal Liberation: The Definitive Classic of the Animal Movement. Updated ed. New York: Harper Collins Publishers, 2009 [1975].

Spencer, Colin. Vegetarianism: A History (Revised Edition of the Heretic's Feast). 2nd ed. New York: Four Walls Eight Windows, 2002. 
Stanescu, Vasile. "Why 'Loving' Animals in Not Enough: A Response to Kathy Rudy, Locavorism, and the Marketing of 'Humane' Meat." The Journal of American Culture 36, no. 2 (2013): 100-10.

Taylor, Chloë. "Foucault and the Ethics of Eating." Foucault Studies 9 (2010): 71-88.

Twigg. Julia. "Food for Thought: Purity and Vegetarianism.” Religion 9 (1979): 13-35.

United States Department of Agriculture. United States: Cattle. N. d. Web. 9 Sep. 2013

Ward, Brenna. "Rednecks, Rig Pigs, and Cowboys: Rural Masculinity in Albertan Country Music.” Spaces Between: An Undergraduate Feminist Journal 1, no. 1 (2013): 1-20.

Weiss, Brad. "Configuring the Authentic Value of Real Food: Farm-to-Fork, Snout-to-Tail, and Local Food Movements.” American Ethnologist. 39, no. 3 (2012): 614-26.

Wolfe, Cary. Animal Rites: American Culture, the Discourse of Species, and Posthumanist Theory. Chicago: The University of Chicago Press, 2003.

-. Before the Law: Humans and Other Animals in a Biopolitical Frame. Chicago: The University of Chicago Press, 2013.

Wright, Will. The Wild West: The Mythical Cowboy and Social Theory. Thousand Oaks: Sage Publications. 